\title{
Paraneoplastic Morvan's syndrome following surgical treatment of recurrent thymoma: A case report
}

\author{
EDVINA GALIÉ ${ }^{1}$, ROSARIA RENNA $^{2}$, DOMENICO PLANTONE ${ }^{1}$, ANDREA PACE $^{1}$, \\ MIRELLA MARINO $^{3}$, BRUNO JANDOLO ${ }^{1}$ and TATIANA KOUDRIAVTSEVA ${ }^{1}$ \\ ${ }^{1}$ Unit of Neurology, Regina Elena National Cancer Institute, Istituti Fisioterapici Ospitalieri, I-00144 Rome; \\ ${ }^{2}$ Institute of Neurology, Catholic University of Sacred Heart, I-00168 Rome; ${ }^{3}$ Department of Pathology, \\ Regina Elena National Cancer Institute, Istituti Fisioterapici Ospitalieri, I-00144 Rome, Italy
}

Received February 9, 2016; Accepted June 3, 2016

DOI: $10.3892 / \mathrm{ol} .2016 .4922$

\begin{abstract}
Morvan's syndrome (MoS) is a rare, complex neurological disorder characterized by neuromyotonia, neuropsychiatric features, dysautonomia and neuropathic pain. The majority of MoS cases have a paraneoplastic aetiology, usually occurring prior to the diagnosis of the underlying tumour and showing improvement following its treatment. The present study reports the case of a 35-year-old Caucasian male patient who was diagnosed with stage IVA thymoma. Thymectomy, lung resection, diaphragmatic pleurectomy and pericardio-phrenectomy were performed 6 months after neoadjuvant chemotherapy. The pathological evaluation revealed a type B2-B3 thymoma with focal squamous differentiation. Two years later, the patient underwent new surgical treatment for a local recurrence of the same histological type, and 4 weeks later, the patient presented with complex neurological symptoms compatible with MoS, including neuromyotonia, neuropsychiatric features, dysautonomia and neuropathic pain. Electromyography was compatible with a diagnosis of neuromyotonia. Brain magnetic resonance imaging scan and tests for serum anti-acetylcholine receptor, anti-striated muscle antibodies and anti-30-kDa titin fragment antibodies were all negative, whereas tests for anti-voltage-gated potassium channel (VGKC)-complex antibodies (333.3 pmol/1), anti-leucine-rich glioma inactivated protein 1 and anti-contactin-associated protein-like 2 antibodies were positive. The patient underwent 3 cycles of intravenous administration of immunoglobulins $(0.4 \mathrm{~g} / \mathrm{kg} /$ day for 5 days every 4 weeks) with little clinical and electrophysiological improvement. We speculated that the late onset of the
\end{abstract}

Correspondence to: Dr Tatiana Koudriavtseva, Unit of Neurology, Regina Elena National Cancer Insitute, Istituti Fisioterapici Ospitalieri, Via Elio Chianesi 53, I-00144 Rome, Italy E-mail: tatiana.koud@gmail.com

Key words: Morvan's syndrome, thymoma, thymic carcinoma, voltage-gated potassium channel-complex antibodies, leucine-rich, glioma inactivated 1 , contactin-associated protein-2 symptoms in the present patient may have been triggered by an increase in the serum level of anti-VGKC antibody, which was caused by the surgery performed for the treatment of recurrent thymoma. To the best of our knowledge, the present report is the first case of MoS associated with this histological type of thymoma uncommonly occurring upon surgical treatment of recurrent thymoma.

\section{Introduction}

Morvan's syndrome $(\mathrm{MoS})$ is a rare, complex neurological disorder characterized by neuromyotonia, neuropsychiatric features (insomnia, confusion, amnesia and hallucinations), dysautonomia (hyperhidrosis, severe constipation, drooling and cardiac arrhythmias) and neuropathic pain (1). It was first described in 1890 by the French physician Augustin Marie Morvan as 'chorée fibrillaire' (2); since then, only $\sim 60$ cases have been reported (1,3-24). Anti-voltage-gated potassium channel (VGKC)-complex antibodies are present in the serum of the vast majority of MoS patients, suggesting an autoimmune aetiology (1). Although these antibodies are directed against leucine-rich, glioma inactivated 1 (LGI-1) protein, contactin-associated protein-2 (Caspr-2) or commonly both, anti-Caspr-2 antibodies are predominant and are always associated with thymoma (1). In fact, patients with MoS may have an associated underlying tumour, such as thymoma (most common), lung cancer, sigmoid cancer, testicular cancer and lymphoma (1). Cases without an associated tumour, usually experiencing a good clinical response to immunotherapy, have also been described (1). Of note, MoS patients with thymomas and myasthenia gravis have also been reported (5).

The present study describes a case of paraneoplastic MoS associated with thymoma in which the characteristic symptoms of MoS occurred following the surgical treatment of the tumour recurrence. Written informed consent was obtained from the patient.

\section{Case report}

In January 2010, a 35-year-old Caucasian male patient was admitted to The Regina Elena National Cancer Institute 


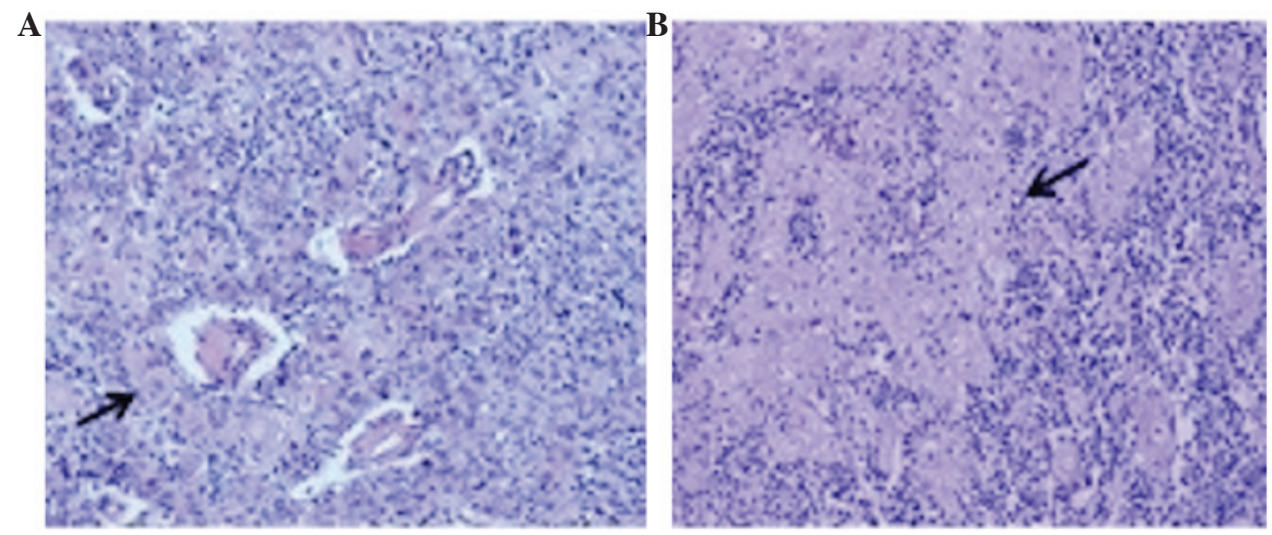

Figure 1. (A) B3 thymoma component (predominant) with squamous differentiation (arrow). (B) B2 thymoma component with squamous differentiation (arrow). Hematoxylin and eosin staining (magnification, x200).

(Rome, Italy) and diagnosed with stage IVA thymoma, according to the Masaoka staging system (25). The patient was subsequently administered 3 cycles of intravenous neoadjuvant chemotherapy consisting of $50 \mathrm{mg} / \mathrm{m}^{2}(92.5 \mathrm{mg}$ total) cisplatin, $50 \mathrm{mg} / \mathrm{m}^{2}$ (92.5 mg total) doxorubicin and $500 \mathrm{mg} / \mathrm{m}^{2}$ (925 mg total) cyclophosphamide on day 1 every 3 weeks. Six months later, the patient underwent thymectomy, right lung resection, partial diaphragmatic pleurectomy and pericardio-phrenectomy, as well as partial neuroablation of the right phrenic nerve. For the pathological evaluation, the tumour tissue was formalin-fixed and paraffin embedded. Sections $(5-\mu \mathrm{m}$ thick) were cut from the paraffin blocks of tumour tissue, placed on glass slides, hydrated by decreasing alcohol percentages and stained with Mayer's heematoxylin and eosin. Slides were then dehydrated, rinsed with xylol and covered by mounting medium. Finally, the slides were covered by coverslips and examined using light microscopy. The pathological evaluation revealed a type B2-B3 thymoma with focal squamous differentiation, according to the World Health Organization criteria (Fig. 1) (26) In addition, prominent areas of keratinization were present (Fig. 1). Following $\mathrm{R} 2$ resection (presence of macroscopic residual tumour), the patient underwent another 2 cycles of 1-day chemotherapy, administered intravenously every 3 weeks, including: Cisplatin, $50 \mathrm{mg} / \mathrm{m}^{2}$ (92.5 mg); doxorubicin, $50 \mathrm{mg} / \mathrm{m}^{2}(92.5 \mathrm{mg}$ ); and cyclophosphamide, $500 \mathrm{mg} / \mathrm{m}^{2}(925 \mathrm{mg})$. The results were consolidated by the adjuvant tridimensional conformal radiotherapy with a total dose of $50 \mathrm{~Gy}$ ( 2 Gy/day, 5 days a week).

Two years later, following a period of clinical stability, the patient presented with local intrathoracic recurrence and underwent wedge resection of multiple lung nodules. Assessment of the recurrent tumour did not reveal any marked changes in tumour histology, confirming a B2-B3 thymoma with focal squamous differentiation. Four weeks after the second surgery, the patient experienced generalized and continuous muscle fasciculations, asthenia, four-limb paresthesias and dysesthesias with mechanical allodynia. Furthermore, the patient reported painful muscular contractions of the legs, hyperhidrosis, weight loss ( 13 kg over 2 months), drooling, generalized itching, impotence, tachycardia, refractory insomnia, agitation, confusion and hallucinations. Upon examination, irregular myoclonic jerks of the four limbs, particularly the upper limbs, were observed. Tendon reflexes were brisk. Plantars were downgoing. Serial electrocardiograms demonstrated sinus tachycardia. Electroencephalogram revealed only diffuse slowing of background rhythm. Nerve conduction studies and electromyography revealed normal motor and sensory nerve conduction velocities, multiple repetitive compound motor action potentials to single stimulation, no decremental response to $2-\mathrm{Hz}$ stimulation of the left axillary nerve, and doublets, triplets, multiplets and continuous neuromyotonic discharges in multiple muscles, including the tongue and facial muscles, without evidence of denervation. These findings were compatible with the diagnosis of neuromyotonia. Brain magnetic resonance imaging scan displayed no obvious findings. Anti-acetylcholine receptor antibodies, anti-striated muscle antibodies, anti-30-kDa titin fragment antibodies were all negative. Genetic analysis for mutations in the gene coding for caveolin-3 yielded negative results. Anti-VGKC-complex antibodies were increased (333.3 pmol/1; normal range $<100 \mathrm{pmol} / \mathrm{l}$ ), and both anti-LGI-1 and anti-Caspr-2 antibodies were detected in the serum.

The patient underwent 3 cycles of intravenous administration of immunoglobulins ( $0.4 \mathrm{~g} / \mathrm{kg} /$ day for 5 days every 4 weeks) with little clinical and electrophysiological improvement. The 36-Item Short-Form Health Survey from the Medical Outcome Study (27) was used to evaluate the quality of life of the patient, who reported a subjective improvement. Evaluation of the levels of anti-VGKC-complex antibodies was repeated after 6 months, and their value (456.2 pmol/l) remained increased. Both anti-LGI-1 and anti-Caspr-2 antibodies were still present.

In November 2013, at the last follow-up, the patient's condition was relatively stable compared with that in May 2013 after the immunoglobulin therapy. The symptoms of excessive sweating, lower limb dysesthesias and some myoclonic jerks of the upper limbs remained. The patient was then lost to follow-up due to relocation to another city. There are no literature data regarding the prognosis of patients with thymoma and MoS, but patients with advanced thymoma have been reported to have a 5-year survival rate of $30-50 \%$ (28).

\section{Discussion}

Since the first description of MoS in 1890 , only a limited number of MoS cases ( 60) have been reported in the literature $(1,3-24)$. 
Currently, MoS is recognized as a rare combination of peripheral nerve hyperexcitability, dysautonomia and encephalopathy. Anti-VGKC-complex antibodies are present in 79\% of cases of MoS, and are usually directed against LGI-1 and Caspr-2 (1). LGI-1 is a key hippocampal protein of synaptic organization that is associated with the subunits of potassium voltage-gated channel subfamily A member 1, connecting preand post-synaptic proteins [a disintegrin and metalloproteinase (Adam)23 and Adam22, respectively] to form a bridge (29). Anti-LGI-1-positive patients usually have a better clinical prognosis than anti-LGI-1-negative patients, which is likely to be dependent on the tumour status $(1,30)$. Caspr-2 is an axonal trans-membrane protein of the neurexin superfamily that binds to contactin-2 (31). It is expressed in the juxta-paranodal region (nodes of Ranvier), hippocampus and cerebellum (32). An association has been reported between high levels of Caspr-2 and a poor prognosis and higher risk of cancer $(1,30)$. Of note, thymectomy and thymoma chemotherapy may act as disease triggers, suggesting that thymic tumours may also harbour the antigenic targets, in particular, Caspr-2 (33).

Clinically, MoS is characterized by peripheral nerve involvement, with neuromyotonia, neuropathic pain, areflexia and a stocking-type sensory loss (1). Insomnia, spatial and temporal disorientation, confusion, amnesia, hallucinations, agitation, epileptic seizures, abnormal behaviours, autonomic disturbance with hyperhidrosis, pruritus, drooling, severe constipation, urinary incontinence, excessive lacrimation, cardiac arrhythmias, weight loss, skin lesions or itching, and hyponatremia due to syndrome of inappropriate antidiuretic hormone secretion, comprise all known possible symptoms $(1,33)$.

The MoS case described in the present report is a clinically and neurophysiologically typical case of paraneoplastic MoS, albeit the description of a B2-B3 thymoma with prominent squamous differentiation represents an unexpected association with MoS; no previous report of such a case was found in the literature. Furthermore, in the present patient, the symptoms of MoS arose a few weeks after the surgery performed for the treatment of local tumour recurrence, whereas the onset of paraneoplastic MoS most commonly occurs prior to the diagnosis of the underlying tumour, and is improved following its treatment (1).

The mechanism through which thymoma triggers autoimmunity has been a matter of debate for several years, and a few different explanations have been proposed (34-36). These theories refer to the failure of positive and negative selection of T-lymphocytes in the thymus, resulting in the alteration of the development of T-cells, producing self-reactive lymphocytes (34). To the best of our knowledge, this is the first case report of MoS associated with a thymoma with prominent squamous differentiation. We can speculate that the late onset of symptoms in the present patient may be triggered by an increase in the serum level of anti-VGKC antibody caused by surgery or by thymoma recurrence itself, confirming that thymic tumours may also harbour antigenic targets, particularly Caspr-2 $(35,36)$.

\section{References}

1. Irani SR, Pettingill P, Kleopa KA, Schiza N, Waters P, Mazia C, Zuliani L, Watanabe O, Lang B, Buckley C and Vincent A: Morvan syndrome: Clinical and serological observations in 29 cases. Ann Neurol 72: 241-255, 2012.
2. Morvan A: De la chorèe fibrillaire. Gazzette Hebdomadaire de Mèdecine et de Chirurgie 27: 173-200, 1890.

3. Robain $\mathrm{O}$ and Attal C: Morvan's analgesic panaris in a 7-year-old child. Arch Fr Pediatr 31: 405-410, 1974 (In French).

4. Murri L, Bonuccelli U, Iudice A and Simonetti C: Sleep disturbances in a case of Morvan's chorea (author's transl). Riv Patol Nerv Ment 97: 350-356, 1976 (In Italian).

5. Lee EK, Maselli RA, Ellis WG and Agius MA: Morvan's fibrillary chorea: A paraneoplastic manifestation of thymoma. J Neurol Neurosurg Psychiatry 65: 857-862, 1998.

6. Jaben EA and Winters JL: Plasma exchange as a therapeutic option in patients with neurologic symptoms due to antibodies to voltage-gated potassium channels: A report of five cases and review of the literature. J Clin Apher 27: 267-273, 2012.

7. Otani S, Kawamura M, Sasaki H, Nakazawa S, Ohara H, Shimada T, Kamitani T, Asato Y, Suzuki M and Sekizuka E: Case report; A case of Morvan syndrome: a paraneoplastic manifestation of angioimmunoblastic T-cell lymphoma. Nihon Naika Gakkai Zasshi 101: 3519-3521, 2012 (In Japanese).

8. Loukaides P, Schiza N, Pettingill P, Palazis L, Vounou E, Vincent A and Kleopa KA: Morvan's syndrome associated with antibodies to multiple components of the voltage-gated potassium channel complex. J Neurol Sci 312: 52-56, 2012.

9. Abou-Zeid E, Boursoulian LJ, Metzer WS and Gundogdu B: Morvan syndrome: A case report and review of the literature. J Clin Neuromuscul Dis 13: 214-227, 2012.

10. Ong E, Viaccoz A, Ducray F, Pérol M, Cavillon G, Rogemond V, Honnorat $J$ and Petiot P: Dramatic improvement after rituximab in a patient with paraneoplastic treatment-refractory Morvan syndrome associated with anti-CASPR2 antibodies. Eur J Neurol 20: e96-e97, 2013.

11. Lukas RV, Rezania K, Malec M and Salgia R: Teaching Video NeuroImages: Myokymia and nerve hyperexcitability as components of Morvan syndrome due to malignant thymoma. Neurology 80: e55, 2013.

12. Sharma S and Sharma P: Morvan syndrome: After scrotal sac drainage and chemical instillation in hydrocele. Neurol India 61: 300-302, 2013

13. Li Y, Ren H, Ren M, Cui F, Yang F, Chen Z, Cui L and Huang X: Morvan syndrome plus thyroid dysfunction: A case with chronic mercury exposure. Neurol India 62: 218-219, 2014.

14. Abgrall G, Demeret S, Rohaut B, Leu-Semenescu S and Arnulf I: Status dissociatus and disturbed dreaming in a patient with Morvan syndrome plus myasthenia gravis. Sleep Med 16: 894-896, 2015.

15. Benedetti L, Franciotta D, Zoccarato M, Beronio A, Godani M, Schirinzi E, Siciliano G, Ciarmiello A and Del Sette M: Post-therapy normalization of brain FDG-PET in Morvan's syndrome. J Neurol Sci 353: 175-176, 2015.

16. Ehler E and Meleková A: Neuromyotonia with polyneuropathy, prominent psychoorganic syndrome, insomnia, and suicidal behavior without antibodies: A case report. J Med Case Rep 9: 101, 2015.

17. Horta Baas G: Intravenous immunoglobulin therapy in Morvan syndrome secondary to recurrent thymic carcinoma. Medwave 15: e6323, 2015 (In Spanish).

18. Baiardi S, Provini F, Avoni P, Pasquinelli M and Liguori R: Immunotherapy of oneiric stupor in Morvan syndrome: Efficacy documented by actigraphy. Neurology 84: 2457-2459, 2015.

19. Laurencin C, André-Obadia N, Camdessanché JP, Mauguière F, Ong E, Vukusic S, Peter-Derex L, Meyronet D, Bouhour F, Vial C, et al: Peripheral small fiber dysfunction and neuropathic pain in patients with Morvan syndrome. Neurology 85: 2076-2078, 2015.

20. Lotan I, Djaldetti R, Hellman MA and Benninger F: Atypical case of Morvan's syndrome. J Clin Neurosci 25: 132-134, 2016

21. Macaron G, El Rassy E and Koussa S: Morvan syndrome secondary to thymic carcinoma in a patient with systemic lupus erythematosus. Case Rep Neurol Med 2016: 9142486, 2016.

22. Mather H: A complicated case of metastatic thymoma. BMJ Support Palliat Care 6: 116-118, 2016.

23. Zhang L, Lu Q, Guan HZ, Mei JH, Ren HT, Liu MS, Peng B and Cui LY: A Chinese female Morvan patient with LGI1 and CASPR2 antibodies: A case report. BMC Neurol 16: 37, 2016.

24. Maskery M, Chhetri SK, Dayanandan R, Gall C and Emsley HC: Morvan syndrome: A case report with patient narrative and video. Neurohospitalist 6: 32-35, 2016.

25. Detterbeck FC, Nicholson AG, Kondo K, Van Schil P and Moran C: The Masaoka-Koga stage classification for thymic malignancies: Clarification and definition of terms. J Thorac Oncol 6 (7 Suppl 3): S1710-S17168, 2011. 
26. Travis WD, Brambilla E, Müller-Hermelink HK and Harris CC (eds): World Health Organization Classification of Tumours Pathology and Genetics of Tumours of the Lung, Pleura, Thymus and Heart. 3rd edition. IARC Press, Lyon, 2004.

27. Ware JE Jr and Sherbourne CD: The MOS 36-item short-form health survey (SF-36). I. Conceptual framework and item selection. Med Care 30: 473-483, 1992.

28. Eng TY, Fuller CD, Jagirdar J, Bains Y, Thomas CR Jr: Thymic carcinoma: State of the art review. Int J Radiat Oncol Biol Phys 59: 654-664, 2004.

29. Kegel L, Aunin E, Meijer D and Bermingham JR: LGI proteins in the nervous system. ASN Neuro 5: 167-181, 2013.

30. Irani SR, Alexander S, Waters P, Kleopa KA, Pettingill P, Zuliani L, Peles E, Buckley C, Lang B and Vincent A: Antibodies to Kv1 potassium channel-complex proteins leucine-rich, glioma inactivated 1 protein and contactin-associated protein-2 in limbic encephalitis, Morvan's syndrome and acquired neuromyotonia. Brain 133: 2734-2748, 2010.

31. Arroyo EJ, Xu YT, Zhou L, Messing A, Peles E, Chiu SY, Scherer SS: Myelinating Schwann cells determine the internodal localization of Kv1.1, Kv1.2, Kvbeta2, and Caspr. J Neurocytol 28: 333-347, 1999.
32. Poliak S, Gollan L, Martinez R, Custer A, Einheber S, Salzer JL, Trimmer JS, Shrager P and Peles E: Caspr2, a new member of the neurexin superfamily, is localized at the juxtaparanodes of myelinated axons and associates with $\mathrm{K}+$ channels. Neuron 24: 1037-1047, 1999.

33. Plantone D, Renna R and Koudriavtseva T: Neurological diseases associated with autoantibodies targeting the voltage-gated potassium channel complex: Immunobiology and clinical characteristics. Neuroimmunol Neuroinflamm 3: 69-78, 2016.

34. Bernard C, Frih H, Pasquet F, Kerever S, Jamilloux Y, Tronc F, Guibert B, Isaac S, Devouassoux M, Chalabreysse L, et al: Thymoma associated with autoimmune diseases: 85 cases and literature review. Autoimmun Rev 15: 82-92, 2016

35. Cottrell DA, Blackmore KJ, Fawcett PRW, Birchall D, Vincent A, Barnard S and Walls TJ: Sub-acute presentation of Morvan's syndrome after thymectomy. J Neurol Neurosurg Psychiatry 75: 1504-510, 2004.

36. Lai M, Huijbers MG, Lancaster E, Graus F, Bataller L, Balice-Gordon R, Cowell JK and Dalmau J: Investigation of LGI1 as the antigen in limbic encephalitis previously attributed to potassium channels: A case series. Lancet Neurol 9: 776-785, 2010. 